\title{
Fusarium Infection Detected in Routine Urine Microscopy in an Immunocompromised Post-Renal Transplant Patient: A Case Report
}

\author{
Dr. Abhishek Gupta ${ }^{1}$, Dr. Sushil K. Shukla ${ }^{2 *}$, Dr. Mansi Kala ${ }^{3}$, Dr. Shahbaj Ahmad ${ }^{4}$, Dr. Anuradha Kusum ${ }^{5}$
}

\author{
${ }^{1}$ Junior Resident, ${ }^{2}$ Senior Resident, ${ }^{3}$ Assistant Professor, ${ }^{5}$ Professor and Head, Department of Pathology, HIHT Medical College, Dehradun, \\ Uttarakhand, 248016, India \\ ${ }^{4}$ Assistant Professor, Department of Nephrology, HIHT Medical College, Dehradun, Uttarakhand, 248016, India
}

DOI: $\underline{10.36348 / \mathrm{sjpm} .2020 . \mathrm{v} 05 \mathrm{i} 03.004}$

| Received: 30.01 .2020 | Accepted: 06.02.2020 | Published: 07.03.2020

*Corresponding author: Dr. Sushil Kumar Shukla

\section{Abstract}

Fusarium is a widely distributed filamentous fungus in plant debris, soil water. Species most repeatedly caught up in human infections are Fusarium solani, F. oxysporum and F. moniliforme. The clinical presentation of fusariosis depends mainly on the immune status of the host. The superficial and localized disease occurs mostly in immunocompetent patients, while invasive and disseminated disease affects mostly immunocompromised patients. The common risk factors for fusariosis to develop include prolonged leukopenia, immunosuppressive drugs and organ transplantation. The present case depicts the finding of spindle shaped structures of fusarium in routine urine examination of immuno-compromised post renal transplant patient.

Keywords: Fusarium, Urine microscopy, Immunocompromised, Post renal transplant.

Copyright @ 2020: This is an open-access article distributed under the terms of the Creative Commons Attribution license which permits unrestricted use, distribution, and reproduction in any medium for non-commercial use (NonCommercial, or CC-BY-NC) provided the original author and sources are credited.

\section{INTRODUCTION}

Fusarium is widely distributed filamentous fungus in the soil, plant debris, organic substrates and in water bodies [1]. Species most repeatedly caught up in human infections are Fusarium solani, F. oxysporum and F. moniliforme. Recently superficial, deep-seated or disseminated infections have been increasing tremendously in immunocompromised patients especially in those patients who are taking immunosuppressive drugs. The clinical forms of fungal infection depend largely on the immune status with superficial or localized disease occurred mostly in immunocompetent while invasive or disseminated disease affecting mostly immunocompromised patients [2]. The common risk factors for fusariosis to develop includes prolonged leukopenia, immunosuppressive drugs and organ transplantation [3].

The prognosis of infection mostly depends upon the degree of immunosuppression and level of infection. These infections may be clinically suspected based on clinical and laboratory findings, which should require prompt therapy for its treatment [2]. So, one should be very vigilant for the detection of fungus, like fusarium especially in the immunocompromised patient, during routine microscopic examination of urine. The present case depicts the finding of fusarium in routine urine examination of immunocompromised post renal transplant patient.

\section{CASE HISTORY}

A 46-year-old Diabetic and hypertensive came to the emergency department with complaints of fever, urgency, increased frequency of urine and dysuria. The patient had received a live renal allograft about five years ago for chronic renal failure of unknown etiology. $\mathrm{He}$ had developed new-onset diabetes after transplantation (NODAT) and had prior history of CNS fungal infection. He was on dual immunosuppressive therapy (Prednisolone \& Tacrolimus) as he developed leucopenia with azathioprine and Mycopheolate. The patient had a toxic look with a blood pressure of 100/ $60 \mathrm{~mm} \mathrm{Hg}$. There was graft tenderness and other systemic examinations were unremarkable. His serum creatinine was elevated to $2.7 \mathrm{mg} / \mathrm{dl}$ from the baseline of $1.2 \mathrm{mg} / \mathrm{dl}$. Hematological investigation showed normocytic normochromic anemia and neutrophilic leukocytosis. Urine examination revealed increased pus cell (55-60/ high power field), presence of bacteria (++) and spindle-shaped fungus (fusarium). So, the provisional diagnosis of acute graft dysfunction because of fungal graft pyelonephritis was made. 
He was started on oral fluconazole and other symptomatic treatments. To avoid Calcineurin toxicity, the dose of tacrolimus was also reduced. The patient had symptomatic improvement along with the decrease of serum creatinine to $1.3 \mathrm{mg} / \mathrm{dl}$.

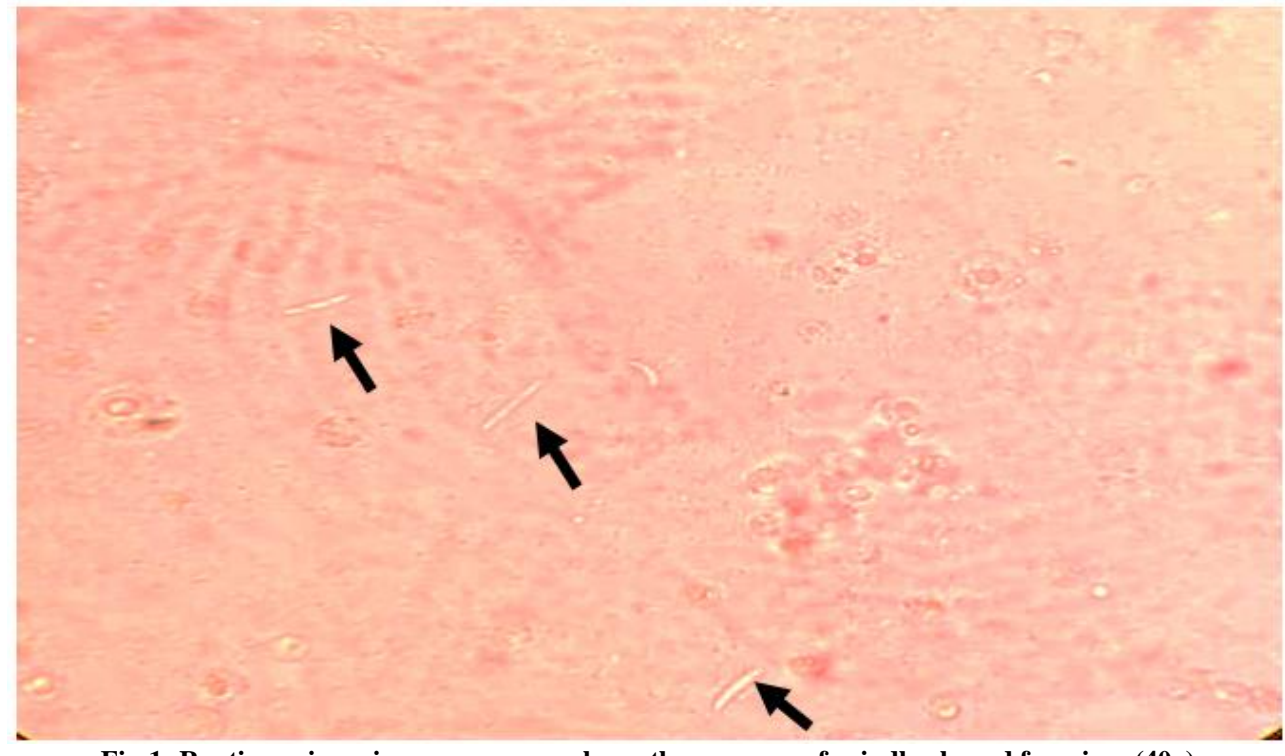

Fig-1: Routine urine microscopy smear shows the presence of spindle-shaped fusarium (40x)

\section{DISCUSSION}

Fusarium species are present in the soil, air and on plants. Growth of most of the species is commonly found in tropical and subtropical areas. They show accelerated growth on SDA at $30^{\circ} \mathrm{C}$ and produce flat, spreading, woolly to cottony colonies [4]. On microscopy, microconidia, macroconidia, conidiophores, or hyaline septate hyphae's are seen. Branched or unbranched conidiophoresphialides produced macroconidia (328611270 $\mathrm{mm})$. Macroconidia are of mostly sickle-shaped or cylindrical with thick-walled and two or more celled. Macroconidia have pointed distal ends with distinct basal foot cell and tend to accumulate in balls or rafts. While microconidia $(2246428 \mathrm{~mm})$ are mostly one celled but can be two or three celled, smooth, hyaline, ovoid to cylindrical, arranged in balls \& occasionally in chains [5]. Fusarium causes localized, focally invasive or disseminated disease in humans [6]. The present rising incidence of infection in the urinary tract by fungus is closely related with widespread and persistent use of immunosuppressive and cytotoxic drugs, broadspectrum antimicrobial agents \& corticosteroids, (1). Other significant risk factors include chronic renal failure, hemodialysis, renal transplantation, higher age, diabetes mellitus, malignancy, nephrolithiasis and abnormalities such as functional or structural abnormalities of the urinary tract with a nephrostomy or indwelling urinary catheter [7]. The pathogen commonly affects immunocompromised individuals, with infection of immunocompetent individuals being rarely reported. Local infection includes cystitis, septic arthritis, endophthalmitis, osteomyelitis and brain abscess was reported in previous literature [3]. In these conditions, a fairly good response may be likely ensuing appropriate oral antifungal therapy and surgery.
Disseminated infection occurs when two or more noncontiguous sites are involved [8]. Fungal urinary tract infections are most commonly caused by Candida species [9]. Urinary tract infections may also be caused by the fungus such as Cryptococcus, Coccidioides, Aspergillus, Histoplasma and Curvularia species [10]. The routine urine microscopy is imperative and primary to diagnosis, since fungus may be detected at an early stage of the disease [1].

Our patient had received a renal allograft and high cumulative dose of immunosuppressive therapy, the latter evidenced by the fact that he had a history of fungal CNS infection. Hence, he was susceptible to opportunistic infections of which the most important one is the fungal infection. Therefore, the diagnosis of fungal graft pyelonephritis was made. Although Amphotericin B has been the drug of choice to treat most fungal infections [2], we used oral fluconazole tablet to treat him as our patient did not show signs of any disseminated infection and azoles, namely fluconazole, voriconazole, posaconazole and ravuconazole, have encouraging results in the cases of zygomycoses [7]. At the last follow-up, there was no symptom of any disseminated fungal disease.

\section{CONCLUSION}

Opportunistic infections in transplant recipients can be life-threatening. Fusarium infections are recognized more often as they can be a cause of significant morbidity and mortality, unless they are diagnosed and treated promptly. The examination of urine microscopy should be done carefully \& one should always be vigilant in the immunocompromised patient for detection of any fungal infection. 


\section{Conflicts of interest: None}

\section{Financial Support: None}

\section{REFERENCES}

1. Krcmery, S., Dubrava, M., \& Krcmery Jr, V. (1999). Fungal urinary tract infections in patients at risk. International journal of antimicrobial agents, 11(3-4), 289-291.

2. Sampathkumar, P., \& Paya, C. V. (2001) Fusarium infection after solid-organ transplantation. Clinical infectious diseases, 32(8), 1237-1240.

3. Louie, T., el Baba, F., Shulman, M., \& JimenezLucho, V. (1994). Endogenous endophthalmitis due to Fusarium: case report and review. Clinical infectious diseases, 18(4), 585-588.

4. Pitt, J. I., Hocking, A. D., Bhudhasamai, K., Miscamble, B. F., Wheeler, K. A., \& Tanboon-Ek, P. (1994). The normal mycoflora of commodities from Thailand. 2. Beans, rice, small grains and other commodities. International Journal of Food Microbiology, 23(1), 35-53.

5. de Hoog, G. S., Guarro, J., Gené, J., \& Figueras, M. J. (2000). Atlas of clinical fungi (No. Ed. 2). Centraalbureau voor Schimmelcultures (CBS).
6. Austen, B., McCarthy, H., Wilkins, B., Smith, A., \& Duncombe, A. (2001). Fatal disseminated fusarium infection in acute lymphoblastic leukaemia in complete remission. Journal of clinical pathology, 54(6), 488-490.

7. Kauffman, C. A., Vazquez, J. A., Sobel, J. D., Gallis, H. A., McKinsey, D. S., Karchmer, A. W., ... \& Mosher, A. (2000). Prospective multicenter surveillance study of funguria in hospitalized patients. Clinical Infectious Diseases, 30(1), 14 18.

8. Kovačičová, G., Špánik, S., Kunova, A., Trupl, J., Sabo, A., Koreň, P., ... \& Jurga, L. (2001). Prospective study of fungaemia in a single cancer institution over a $10-y$ period: aetiology, risk factors, consumption of antifungals and outcome in 140 patients. Scandinavian journal of infectious diseases, 33(5), 367-374.

9. Vartivarian, S. E., Anaissie, E. J., \& Bodey, G. P. (1993). Emerging fungal pathogens in immunocompromised patients: classification, diagnosis, and management. Clinical infectious diseases, 17(Supplement_2), S487-S491.

10. Robson, A. M., \& Craver, R. D. (1994). Curvularia urinary tract infection: a case report. Pediatric Nephrology, 8(1), 83-84. 